\title{
Analysis of U.S. Transportation Industry Based on Fama-French 5-Factor Model under COVID-19
}

\author{
Jiayi $\mathrm{Hu}^{1, *}$ \\ ${ }^{1}$ Department of Chemistry, Renmin University of China, Beijing 100872, China \\ *Corresponding author. Email: 2018201088@ruc.edu.cn
}

\begin{abstract}
The outbreak of the COVID-19 has had a great impact on the U.S. economy and society. A lot of researchers have applied Capital Asset Pricing to the analysis of stock markets. This paper aims to utilize Fama-French 5-Factor Model to reveal the changes of stocks and markets in the transportation industry in the U.S. before and after the COVID-19 and the possible reasons for these changes. Based on the data of transportation industry stocks from May 2019 to December 2020, the regression results show that the Autos industry is less sensitive than the whole market after the outbreak. The investment factor is not that obviously influential, with the profitability Autos industry decreasing significantly. For the Aero industry, the coefficients $\beta_{\mathrm{SMB}}$ and $\beta_{\mathrm{HML}}$ were redundant before the pandemic, while those after the pandemic turn to be significant. It means that after the COVID-19, small-cap stocks can receive higher returns, and the HML factor has begun to become significant in the Aero industry, which can better analyse the stock return. Besides, before the COVID-19, the coefficient $\beta_{\mathrm{CMA}}$ of the Ships industry was redundant. Still, it becomes significant after the COVID-19, probably because the market was relatively scattered and fluctuates greatly before the outbreak of the epidemic. Therefore, CMA may not be a suitable factor for market measurement. Through comparisons and analysis, this article indicates the stock market changes in the transportation industry, and it can be of benefit to investors as well as the government when making decisions and formulating policies.
\end{abstract}

Keywords: COVID-19, Fama-French Model, Transportation Industry, U.S. stock market.

\section{INTRODUCTION}

Before the COVID-19 pandemic started and spread, the development of the economy and society in the United States was in a steady state. Then after February 2020, with the outbreak of the COVID-19 pandemic, the demand and supply of the US economy were subjected to structural shocks. Under this background, many enterprises stopped production, and the capital market was severely influenced as well. After a short period, the stock market suffered a serious decline, accompanied by an obvious tendency for interest rate cuts and selling. This crisis also greatly impacted transportation, including autos, aero and ships, which produced a huge effect on the stock market and people's preference about transport.

Capital Asset Pricing has established the relationship between capital risk and return, clearly stating that the expected return rate of securities is the sum of the riskfree return rate and risk compensation, revealing the internal structure of securities returns. What's more, the practical significance is applied to asset valuation, capital cost budgeting and resource allocation, and it can be called the pillar of modern financial market price theory. This kind of system divides risks into nonsystemic risk and systemic risk. Non-systemic risk is a risk unique to a particular company or industry, and it is a risk that can be diversified through asset diversification. Systemic risk refers to the risk factors that affect the entire market, and it is the inherent risk of the stock market itself, which cannot be eliminated through diversification. The role of the capital asset pricing model is to diversify non-systemic risk through investment portfolios, leaving only systemic risk. And the $\beta$ coefficient is introduced into the model to characterize the systemic risk in the model.

The COVID-19 pandemic has been giving a heavy blow to macroeconomics in the U.S. in different aspects of society. To provide real-time forward-looking uncertainty measures, Baker et al. identified three indicators - stock market volatility, newspaper-based economic uncertainty, and subjective uncertainty in business expectation surveys. By using these indicators, Baker et al. documented and quantified the enormous 
increase in economic uncertainty in the past several weeks, also illustrating how these forward-looking measures can be used to assess the macroeconomic impact of the COVID-19 crisis [1].

In addition, for the transportation industry, there was a serious impact caused by COVID-19, while the U.S. may not have adequate preparation and response. Zhang et al. considered the various uncertainties and unknowns about this virus and its impacts (especially long-term impacts). Based on extensive analyses of the survey results, Zhang et al. first revealed the realities of lockdowns, restrictions of out-of-home activities and other physical distancing requirements, as well as modal shifts. Analysis results revealed that our human society was unprepared for the current pandemic, reaffirming the importance of risk communication [2]. Loske identified that governmental restrictions aspiring to slow down the spread of epidemic and pandemic outbreaks lead to impairments for economic operations, impacting transportation networks comprising the maritime, rail, air, and trucking industries. Loske analysed the transport volume of $\mathrm{n}=15,715$ routes in the timeframe of 23.03.2020 to 30.04.2020, a transport volume growth rate expressing the difference of real and expected transport volume was calculated. This ratio was then examined concerning the number of COVID-19 infections per day. This study proves that the increasing freight volume for dry products in retail logistics does not depend on the duration of the COVID-19 epidemic but on the strength quantified through the total number of new infections per day. This causes a conflict of interest between transportation companies and food retail logistics for non-cooled transport capacity [3]. Calderon-Tellez and Herrera used modelling-based scenario analysis to assess the restriction policies relating to air transport in Argentina, Brazil and Colombia during and after the pandemic and their effects on the environment. The simulation results highlight the need to reduce the negative environmental impact produced by the aviation sector and suggest that policymakers should try to focus on creating ways to reduce the impact made by the aviation industry on the environment through a coordinated environmental policy between countries [4]. Panayides et al. identified that the water transportation of freight had been one of the most important sectors in facilitating international trade and contributing to the growth of the world economy. Bearing in mind the importance of the relationship between asset returns and liquidity in water transportation, Panayides et al. examined this relation within the context of US-traded international water freight transportation firms. Using a Fama-MacBeth analysis shows that the illiquidity risk premium is priced in the water transportation sector beyond the Fama and French and market-wide illiquidity risk factors, indicating higher average returns for stocks with greater illiquidity measures. It is also shown that the market- wide illiquidity factor and the Fama-French SMB and HML risk factors are significant in explaining stock returns [5]. Gudmundsson et al. estimated the relationship between the strength of economic shocks and temporal recovery in the world air transport industry. The results showed that the strength of economic shocks of various origins impacts the linear growth of passenger and freight traffic and the temporal recovery of the industry in a predictable transitory way. Hence, the impact of the COVID-19 recession will represent a temporary, although long-lasting, correction to previous growth levels [6].

People's travel demand and preference for different ways of transportation have also changed due to the COVID-19 pandemic. Falchetta and Noussan researched the Potential long-run impacts on total travel demand, potential long-run impacts on modal shares and long-run repercussions for transport energy consumption and emissions. Through discussion, Falchetta and Noussan suggested that high uncertainties characterise the longer-run impacts of COVID-19 on energy demand from the transport sector. This is because the supply and demand sides are each reacting in complex ways, with a prominent role of digital telecommunications in reducing the need for transport of people [7]. Almlf et al. reckoned that the COVID-19 pandemic has changed travel behaviour and reduced the use of public transport throughout the world, but the reduction has not been uniform. By analysing the propensity to stop travelling by public transport during COVID-19 for the holders of 1.8 million smart cards in Stockholm, Sweden, Almlf et al. linked socioeconomic data with the probability to stop travelling. Furthermore, Almlf et al. used clustering to divide the population into five separate social groups, serving as a more intuitive understanding of how the pandemic has affected different citizens' propensity to use public transport [8].

To analyse the problems about market and investment, Fama and French introduced the FamaFrench 5-factor model (FF5F). Fama and French identified five common risk factors in the returns on stocks and bonds. There are three stock-market factors: an overall market factor and factors related to firm size and book-to-market equity. There are two bond-market factors related to maturity and default risks. Stock returns have shared variation due to the stock-market factors, and they are linked to bond returns through shared variation in the bond-market factors. Except for low-grade corporates, the bond-market factors capture the common variation in bond returns. Most importantly, the five factors seem to explain average returns on stocks and bonds [9].

There is an example of using FF5F to analyse market changes. Hou and Chen analysed the market changes of the American steel industry before and after the epidemic based on the Fama-French 5-factor model 
(FF5). The Data from Kennethr French-Data Library were used to make multiple regression analyses of the U.S. steel industry before and after the epidemic. The Fama-French 5-factor model was also used for analysis. According to the results of multiple linear regression, due to the influence of COVID-19, the coefficient of market risk (Betam) decreased; Robust minus Week (RMW) changed from significant to insignificant; Small minus Big (SMB) and High minus Low (HML) were significant, and the change of epidemic situation was not significant, while Conservative minus Aggressive (CMA) was not significant. The outbreak's impact on the U.S. steel industry has been dramatic and has led to a huge decline in the entire industry [10].

So far, few scholars have studied the changes in the stock market in the transportation industry in the U.S. before and after the COVID-19 epidemic, and there is a lack of certain data regression analysis. In this paper, FF5F is intended to be used to analyse the changes in markets and stocks in the U.S. transportation industry before and after the COVID-19 pandemic. The FamaFrench 5-factor model is effective to help investors make their decisions in the transportation industry during the period when the COVID-19 pandemic still exists.

\section{METHOD}

\subsection{Capital Asset Pricing Model Theory}

The Capital Asset Pricing Model (CAPM) was developed based on portfolio theory and capital market theory in 1964. It mainly studies the relationship between the expected rate of return of assets and risk assets in the securities market and how the equilibrium price is formed. This model occupies a dominant position in modern financial theory. However, the model mainly analyses the sensitivity of securities and market portfolio returns without considering other factors.

When the capital market reaches equilibrium, the marginal price of risk is unchanged, and the marginal effect of any investment that changes the market portfolio is the same. That is, the compensation for adding one unit of risk is the same. According to the definition of $\beta$, substituting into the equilibrium capital market conditions, the capital asset pricing model is obtained:

$$
E\left(R_{i}\right)=R_{f}+\beta_{i m}\left(E\left(R_{m}\right)-R_{f}\right)
$$

Where $E\left(R_{i}\right)$ is the expected return on asset, $E\left(R_{m}\right)$ is the expected return on the market, $R_{f}$ is the risk-free rate, $\beta_{i m}$ is the Beta coefficient, which is the systemic risk of the asset.

\subsection{Fama-French Three-Factor Model Industry}

In 1993, Fama and French introduced the FamaFrench 3-factor model (FF3F), which expands on CAPM by including two new factors: size and book-tomarket. The FF3F performs better on stock return estimation when the two new risk factors work with CAPM's original market risk factor. The size of a firm is represented as market capitalization (ME):

$\mathrm{ME}=($ share price $) *($ number of outstanding shares in issue)

The book-to-market ratio (BE/ME), meaning value premium of a firm, reflects the firm's book value to market value:

$$
\frac{B E}{M E}=\frac{\text { Book Value of Equity }}{M E \text { Market Value of Equity }}
$$

The size and book-to-market values are captured in two portfolios, "Small minus Big" (SMB) and "High minus Low" (HML), respectively, in Fama and French's model. They explained the fact that small-cap stocks usually outperform markets while high-value premium stocks also tend to generate higher returns.

In FF3F, the expected return of asset $\mathrm{i}$ can be estimated as:

$E\left(R_{i}\right)-R_{f}=\alpha+\beta_{1} *\left[E\left(R_{m}\right)-R_{f}\right]+\beta_{2} * S M B+\beta_{3} * H M L+\varepsilon_{i}$

where $E\left(R_{i}\right)$ is the expected return on asset, $R_{m}$ is the expected return on the market, $R_{f}$ is the risk-free rate, $S M B$ and $H M L$ refer to size premium and value premium, respectively, and $\beta$ means factors coefficients.

\subsection{Fama-French Five-factor Model Theory}

In 2013, Fama and French found that in addition to the above risks, profitability risk and investment level risk can also bring excess returns of individual stocks, and published the Fama-French 5-factor model (FF5F). It comprehensively considers the impact of system risk, book value ratio, market value scale factor, profit factor and investment factor on fund performance, evaluating fund performance and measuring the ability of the fund to obtain excess returns through active investment management more effectively. The five-factor model is as follows:

$$
\begin{aligned}
& E\left(R_{i}\right)-R_{f}=\alpha+\beta_{1} *\left[E\left(R_{m}\right)-\right. \\
& \left.R_{f}\right]+\beta_{2} * S M B+\beta_{3} * H M L+\beta_{4} * R M W+\beta_{5} * C M A+\varepsilon_{i}
\end{aligned}
$$

The two additional factors are RMW and CMA, accounting for profitability and investment factor, respectively, and in this new model, the value premium factor becomes redundant.

For factor RMW (Robust Minus Weak), the difference between the high-profit rate and the low- 
profit rate of the stock portfolio reflects the premium of the high-profit stock investment relative to the lowprofit one. Higher risks generally accompany industries with higher profitability. In addition, Conservative Minus Aggressive (CMA) is an investment style factor. The difference between a conservative investment style and a radical investment style of stock portfolio returns reflects the high investment ratio model compared to the low investment ratio model. It is generally believed that companies with low investment rates are riskier, and they have higher requirements for return on these companies. On the contrary, companies with higher investment rates usually have less risk than those with low investment rates.

\section{RESULTS}

The data is processed with the above method within the time range from May 2019 to February 2020(Before) compared with the time range from March 2020 to December 2020(After). The fitting results of the 5factor model of these two periods of time are derived by multiple linear regression (MLR), respectively.

Table 1. Regression results in Autos

\begin{tabular}{ccccc}
\hline & \multicolumn{2}{c}{ Before } & \multicolumn{2}{c}{ After } \\
\cline { 2 - 5 } Factors & Coefficients & $\mathrm{t}$ Stat & Coefficients & $\mathrm{t}$ Stat \\
\hline Intercept & 0.031 & 0.584 & 0.227 & 2.973 \\
MKT-R $_{\mathrm{f}}$ & 1.029 & 16.405 & 0.913 & 25.549 \\
SMB & 0.982 & 8.355 & 0.992 & 10.809 \\
HML & 0.404 & 3.350 & 0.312 & 4.182 \\
RMW & 0.891 & 4.507 & 0.457 & 2.991 \\
CMA & -0.182 & -0.781 & -0.212 & -1.087 \\
\hline
\end{tabular}

Table 2. Regression results in Aero

\begin{tabular}{ccccc}
\hline & \multicolumn{2}{c}{ Before } & \multicolumn{2}{c}{ After } \\
\cline { 2 - 5 } Factors & Coefficients & t Stat & Coefficients & t Stat \\
\hline Intercept & 0.018 & 0.333 & 0.173 & 1.216 \\
MKT-R $_{\mathrm{f}}$ & 0.945 & 14.342 & 0.954 & 14.335 \\
SMB & 0.219 & 1.775 & 0.825 & 4.823 \\
HML & 0.071 & 0.559 & 0.734 & 5.274 \\
RMW & -0.068 & -0.325 & 0.373 & 1.311 \\
CMA & 0.350 & 1.434 & -0.697 & -1.918 \\
\hline
\end{tabular}

Table 3. Regression results in Ships

\begin{tabular}{ccccc}
\hline & \multicolumn{2}{c}{ Before } & \multicolumn{2}{c}{ After } \\
\cline { 2 - 5 } Factors & Coefficients & t Stat & Coefficients & t Stat \\
\hline Intercept & -0.058 & -0.858 & 0.058 & 0.590 \\
MKT- $_{\mathrm{f}}$ & 0.965 & 12.036 & 0.926 & 20.160 \\
SMB & 1.099 & 7.317 & 0.881 & 7.469 \\
HML & 0.601 & 3.902 & 0.466 & 4.851 \\
RMW & 0.439 & 1.736 & -0.123 & -0.625 \\
CMA & -0.184 & -0.619 & -0.592 & -2.361 \\
\hline
\end{tabular}

As shown in Table 1, for Autos, the $t$ Stat of intercept of the period of time from May 2019 to February 2020 does not show significance, while the $\mathrm{t}$ Stat of the period of time from May 2019 to February 2020 shows. Besides, the $\beta C M A$ in both periods does not show significance. In addition, as Table 2 illustrated by using the Fama-French 5-factor model, for Aero, the t Stat of intercept, $\beta_{\mathrm{RMW}}$ and $\beta_{\mathrm{CMA}}$ of both periods are insignificant. But in particular, the $t$ Stat of $\beta_{\mathrm{SMB}}$ and $\beta_{\mathrm{HML}}$ of the period of time from May 2019 to February
2020 turn to be redundant, while that of the period of time from March 2020 to December 2020 is significant. According to Table 3, for Ships, the t Stat of intercept, $\beta_{\mathrm{RMW}}$ of both periods remain redundant. And $\beta_{\mathrm{CMA}}$ of the period of time from May 2019 to February 2020 is also redundant, but that of the period of time from March 2020 to December 2020 shows significance.

\section{DISCUSSION}

The outbreak of COVID-19 has had a great influence on the transportation industry. This study evaluates different degrees of changes in different ways of transportation before and after the pandemic, analysing and comparing the coefficients and their validity. Aiming to provide a more reliable and complete result, this study also combines the industry background with the actual situation, exploring the possible reasons for changes and differences.

\subsection{Autos}

Though the results indicate that the $t$ Stat of interception in the period from March 2020 to December 2020 does show significance, the FamaFrench 5-Factor model could not fit very well to reflect the market and investment situations of the Autos industry after the COVID-19. Maybe this phenomenon is because there are some other factors besides these five ones, such as people's preference of travel or policy published by the government.

It appears that the coefficient $\beta_{\text {MKT-Rf was more than }}$ 1 before the pandemic and closer to 1 , while after the outbreak, the coefficient $\beta_{\text {MKT-Rf }}$ is less than 1 . It illustrates that the Autos industry was less sensitive than the whole market from March 2020 to December 2020. Still, shares approximated the same sensitivity as the whole market from May 2019 to February 2020. One possible reason is given by the reduction of Auto travel during the quarantine period when demands for traveling fall down. Due to the hope to reduce the risk of infection, reduction of demands caused the decline of supply. What's more, the coefficient $\beta_{\mathrm{RMW}}$ after the pandemic is nearly half of that before the pandemic, which means that the profitability of the Autos industry decreased significantly, perhaps because of the falling of productivity of raw and processed materials as well as the rising production costs. Besides, the coefficient $\beta_{\mathrm{CMA}}$ is redundant before and after the COVID-19, which shows that the investment factor is not that obviously influential when it comes to the Autos industry.

\subsection{Aero}

As shown in Table 2, it reveals that the coefficients $\beta_{\mathrm{SMB}}$ and $\beta_{\mathrm{HML}}$ were redundant before the pandemic while those after the pandemic turn to be significant. 
That means that after the COVID-19, small-cap stocks can receive higher returns. The statistic test results support that the SMB factor is significant in return prediction. Influenced by the pandemic, the SMB coefficient increases to 0.824 from about 0.219 , respectively. This increasing relationship between SMB and asset return reflects a stronger intention of high returns in small-cap stocks. Besides, for the data after the pandemic, the HML factor becomes significant, which indicates that companies with high book-tomarket value ratios have a higher probability of profit. The reason is that owing to the pandemic, the development of aviation has become distinguished between private enterprise and state-owned enterprise. During the COVID-19 pandemic, these private enterprises or small enterprises in the Aero industry have all experienced economic downward. Their operations have almost stagnated as if they were forced to withdraw from the market. These low book-to-market value companies are being lost, while the high book-tomarket value manufacturing companies are left. Therefore, the HML factor has begun to become significant in the Aero industry and can better analyse the stock return. Besides, the coefficients $\beta_{\mathrm{RMW}}$ and $\beta_{\mathrm{CMA}}$ are both redundant according to the results, demonstrating that profitability and investment factors are not significant in the Aero industry market.

\subsection{Ships}

The data shows that the coefficient $\beta_{\mathrm{RMw}}$ is redundant in both periods of time, that is, the profitability factor is not that significant, especially for the period of time from March 2020 to December 2020. However, it shows a great difference in the coefficient $\beta_{\text {CMA }}$. Before the COVID-19, the coefficient $\beta_{\mathrm{CMA}}$ was redundant, but it becomes significant after the COVID19. CMA is designed to capture the difference between the returns on diversified portfolios of the stocks of low and high investment firms. According to the result, $\beta_{\mathrm{CMA}}$ was a redundant variable of the 5-factor model before the pandemic, but it becomes valid in the model for data collected after the outbreak $\left(\beta_{\mathrm{CMA}}=-0.592\right)$. Because the Ships industry is relatively various with different kind of companies. Therefore, the market was comparatively dispersive and enjoyed higher volatility before the outbreak. Thus, CMA is probably not a suitable factor for market measurement.

\section{CONCLUSION}

This article employs the Fama-French 5-Factor Model to analyse the stock and market changes in the transportation industry with the regression results based on the data before and after the COVID-19. It indicates that before and after the epidemic outbreak, different factors have different impacts on the Autos, Aero and Ships industries. Based on the analysing results about the stock market of the transportation industry, investors can be able to make appropriate and informed decisions to obtain more benefits. It also reveals the reasons for the stock and market changes during the pandemic, which is available to be referenced by transportation sections or government when they intend to make plans to adjust the transportation stock market and the development of the transportation industry.

\section{REFERENCES}

[1] Baker, S. R., Bloom, N., Davis, S. J., \& Terry, S. J. (2020). COVID-Induced Economic Uncertainty. National Bureau of Economic Research.

[2] Zhang, J., Hayashi, Y., \& Frank, L. D. (2021). COVID-19 and Transport: Findings from a Worldwide Expert Survey. Transport Policy, 103, 68-85.

[3] Loske, D. (2020). The impact of COVID-19 on transport volume and freight capacity dynamics: An empirical analysis in German food retail logistics. Transportation Research Interdisciplinary Perspectives, 6(6), 100165-100165.

[4] Calderon-Tellez, J., \& Herrera, M. M. (2021). Appraising the impact of air transport on the environment: lessons from the covid-19 pandemic. Transportation Research Interdisciplinary Perspectives, 100351

[5] Panayides, P. M., Lambertides, N., \& Cullinane, K. . (2013). Liquidity risk premium and asset pricing in us water transportation. Transportation Research Part E Logistics \& Transportation Review, 52(jun.), 3-15.

[6] Gudmundsson, S. V., Cattaneo, M. , R Redondi, \& Graham, A. . (2021). Forecasting temporal world recovery in air transport markets in the presence of large economic shocks: The case of COVID-19.

[7] Falchetta, G., \& Noussan, M.. (2020). The Impact of COVID-19 on Transport Demand, Modal Choices, and Sectoral Energy Consumption in Europe.

[8] Almlf, E., Rubensson, I., Cebecauer, M., \& Jenelius, E. (2020). Who is still travelling by public transport during COVID-19? Socioeconomic factors explaining travel behaviour in Stockholm based on smart-card data.

[9] Fama, E. F., \& French, K. R. (1993). Common risk factors in the returns on stocks and bonds. Journal of Financial Economics, 33(1), 3-56.

[10] Hou, D., \& Chen, Z. . (2021). Research on the application of fama-french 5-factor model in the steel industry during covid-19. Journal of Physics: Conference Series, 1865(4), 042104 (5pp). 